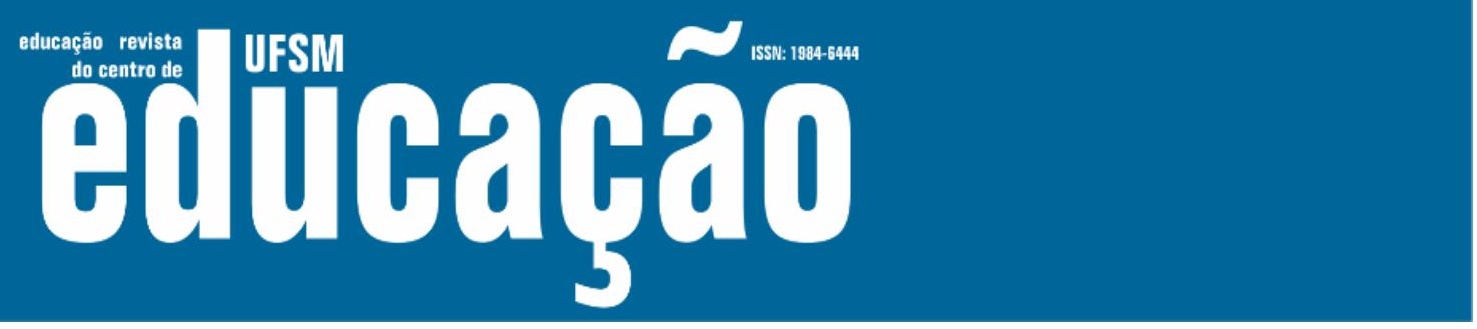

ISSN: 1984-6444 | http://dx.doi.org/10.5902/1984644448049

\title{
História Oral das mulheres usuárias da Assistência Social: diálogos com a Educação Não Formal
}

\author{
Oral History of Women Social Assistance Users: Dialogues with Non- \\ Formal Education
}

Patrícia Cristina Antonietto

Mestre em Educação pelo Centro Universitário Salesiano São Paulo. São Paulo, Brasil. pantonietto@yahoo.com.br - https://orcid.org/0000-0002-3354-8238

Lívia Morais Garcia Lima

Pós-doutoranda na Universidade Federal de São Paulo - UNIFESP. São Paulo, Brasil. liviamglima@gmail.com - http://orcid.org/0000-0001-9962-7820.

Recebido em 07 de julho de 2020

Aprovado em 15 de junho de 2021

Publicado em 27 de janeiro de 2022

\section{RESUMO}

O presente trabalho visa conhecer e analisar os significados que as usuárias atribuem às ações educativas desenvolvidas nos serviços de Proteção e Atendimento Integral à Família e Serviço de Convivência (PAIF) e Fortalecimento de Vínculos (SCFV) na cidade de Americana/SP, concebidos pela Política Nacional de Assistência Social. A revisão bibliográfica subsidiou a pesquisa de campo, utilizando-se para tal a metodologia de História Oral, na modalidade de depoimento oral. É por meio das vozes das mulheres que os efeitos da ação educativa desenvolvida nos serviços se fazem conhecer, assinalando a importância dos espaços grupais como mediadores da aprendizagem e de perspectivas para o fortalecimento dos vínculos comunitários, uma vez que permitem a identificação e percepção de classe, de coletivo. A História Oral desvela outra realidade que para a mídia não interessa mostrar. Por fim, a nebulosa relação entre Assistência Social e Educação Não Formal, que pode contribuir para o fortalecimento grupal, combinando novas possibilidades metodológicas da Educação Não Formal com o poder de alcance que o status de política social dá à Assistência Social.

Palavras-chave: Educação Não Formal; Assistência Social; História Oral. 


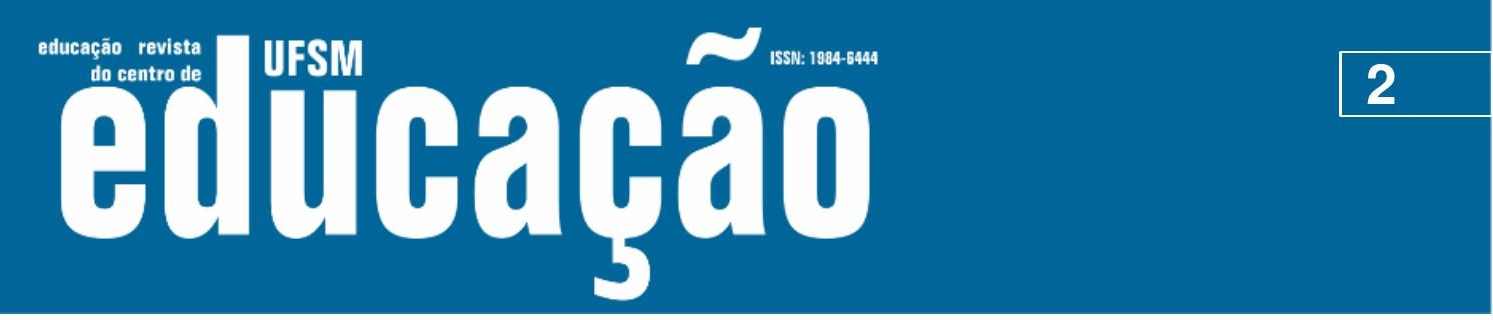

ISSN: 1984-6444 | http://dx.doi.org/10.5902/1984644448049

\section{ABSTRACT}

The present work aims to know and analyze the meanings that the users attribute to the educational actions developed in the services of Protection and Integral Assistance to the Family and Coexistence Service (PAIF) and Strengthening of Links (SCFV) in the city of Americana/SP, conceived by the Policy National Social Assistance. The bibliographic review supported the field research, using the Oral History methodology for this, in the form of oral testimony. It is through the voices of women that the effects of the educational action developed in the services are made known, pointing out the importance of group spaces as mediators of learning and perspectives for the strengthening of community bonds, since they allow the identification and perception of class, of collective. Oral history unveils another reality, which the media is not interested in showing. Finally, the nebulous relationship between Social Assistance and Non-Formal Education, which can contribute to group strengthening, combining new methodological possibilities of Non-Formal Education with the reach power that the social policy status gives to Social Assistance.

Keywords: Non-Formal Education. Social Assistance. Oral History.

\section{Introdução}

As últimas décadas foram marcadas por mudanças importantes nos âmbitos econômico e produtivo, pela adoção de políticas de caráter neoliberal unidas às inovações tecnológicas que substituíram os postos de trabalho, contribuindo para o aprofundamento da chamada questão social, que se materializa na pobreza, na fome, na violência e em outros problemas que assolam a sociedade, e que tem sido 'combatida' por meio de políticas públicas, especialmente a política de Assistência Social. No entanto, há ainda, outra faceta dessa questão social: a pobreza política.

A pobreza política torna ainda mais grave tal situação, pois veta possibilidades de enfrentamento da desigualdade em suas raízes. A adoção de políticas que promovam a participação social é essencial para o combate de sua própria pobreza, de acordo com Demo (1996). Do mesmo modo, Gohn (2001) afirma que a defesa das culturas e identidades é fundamental para o reconhecimento e desenvolvimento das potencialidades dos sujeitos para uma leitura crítica e transformação da realidade que vivenciam. 


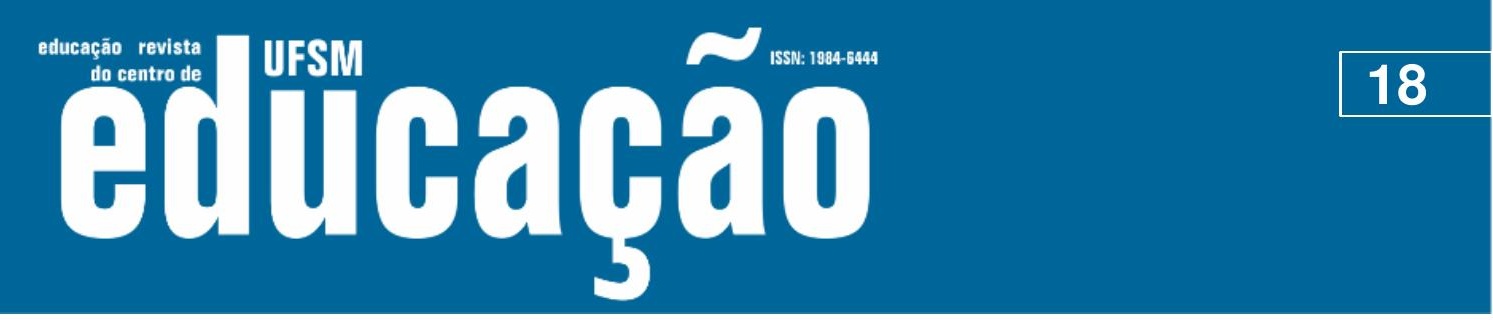

ISSN: 1984-6444 | http://dx.doi.org/10.5902/1984644448049

\section{Considerações Finais}

A compreensão da relação entre Educação Não Formal e Assistência Social implica em saber que nenhuma política é neutra, e as políticas sociais, de modo geral, surgem para dar resposta aos efeitos nefastos da exploração capitalista, geradora de desigualdade. Não se trata de um ato benevolente das classes dominantes, mas é uma resposta necessária às lutas das classes subalternas.

Historicamente, o pobre tem sido visto como perigoso, e de fato o é: a revolta das camadas empobrecidas (que no sistema capitalista são a maioria) pode pôr em risco a legitimidade do sistema, portanto, nessa lógica, a pobreza deve ser controlada. Em cada época, e conforme as características de desgaste do capital, as classes dominantes, via Estado, apresentam uma intervenção para o controle dos subalternos: seja oferecendo direitos e serviços públicos pelas políticas sociais, ou reduzindo a oferta destes. Essa é a face atual da política social: a construção da seguridade num contexto de desconstrução do Estado, com a privatização da saúde, da Assistência Social (por meio do terceiro setor), e Previdência Social, pelas reformas constantes.

Embora a Assistência Social seja uma política social que, tradicionalmente, tem atuado no enfrentamento da questão social (esta por sua vez, se expressa pelas questões ligadas ao gênero, à etnia/raça, à classe social), numa relação dúbia com o capital - ora favorecendo, ora se opondo - se utilizando de práticas educativas para produzir as mudanças consideradas necessárias para a implementação de seus objetivos. Especialmente, se utiliza do campo da Educação Não Formal, uma vez que, o ensino não é parte de suas atribuições como política social.

A Educação Não Formal é aqui entendida como um campo de saber e de fazer em construção e distinto da educação escolar, modelo adotado como política social. A Educação Não Formal se caracteriza e se difere por contemplar outras metodologias de ensino/aprendizagem, flexibilidade nos tempos e de compreender o educador como um mediador na aprendizagem, tendo assim, uma possibilidade de aplicação em diferentes áreas da vida.

Os principais achados da pesquisa foram: as mulheres entrevistadas não cresceram no território, portanto ele não faz parte de suas memórias antigas e nem 


\section{Aillbapẫ}

ISSN: 1984-6444 | http://dx.doi.org/10.5902/1984644448049

Nas vozes das entrevistadas ficou evidente a motivação para a participação espontânea no grupo: poder falar. A princípio pode parecer simplório, até bizarro; mas se trata de falar e ser ouvida. Ser ouvida não é ser interrompida e receber orientações; falar e ser ouvida é não ser reprimida, não ser julgada; é ter sua fala problematizada como algo precioso a ser trabalhado, lapidado.

Sim, as mulheres vão ao grupo para falar sobre si, sobre seus companheiros, filhos, sobre as lutas e alegrias cotidianas, sobre seus sonhos e desventuras. Dividem o que deu certo e o que lhes atormentam. Pedem conselho, recebem a devolutiva; há também o embate de ideias e culturas; falam de seus relacionamentos, de sua condição de mulher, na família e na sociedade.

A atividade grupal permite a identificação e favorece a percepção de classe, de coletivo - tão atacada pelo ideário individualista no capitalismo. Ainda conforme as falas das entrevistadas, percebe-se que, para muitas, o PAIF/SCFV é o único espaço coletivo que efetivamente participam. Isso evidencia a importância e a potência dessas atividades junto às classes subalternas, para a formação e consolidação de vínculos comunitários.

No grupo se percebem como gênero, com problemáticas coletivas ao invés da 'tragédia pessoal'. A adesão a esse grupo, em relação a outras experiências grupais, denota a importância de práticas que remetam aos interesses reais dos participantes, logo a concepção das atividades deveria ser compartilhada com eles, o que ainda não ocorre efetivamente. Apontam ganhos pela e na convivência intergeracional. Os aprendizados identificados pelas participantes são proeminentes no âmbito do relacionamento interpessoal, mas tímidos enquanto coletividade, ao que se conclui que o fazer junto que a Animação Sociocultural promove pelas atividades culturais, poderia favorecer a autonomia do grupo. Deveras, a atividade grupal promove o compartilhamento dos saberes individuais e coletivos (nas memórias, crenças, interesses comuns), que alcança também o educador (assistente social) e outros funcionários das instituições promotoras, que criam laços com essas mulheres, transbordando a relação institucional, afetando também suas perspectivas pessoais e profissionais. 


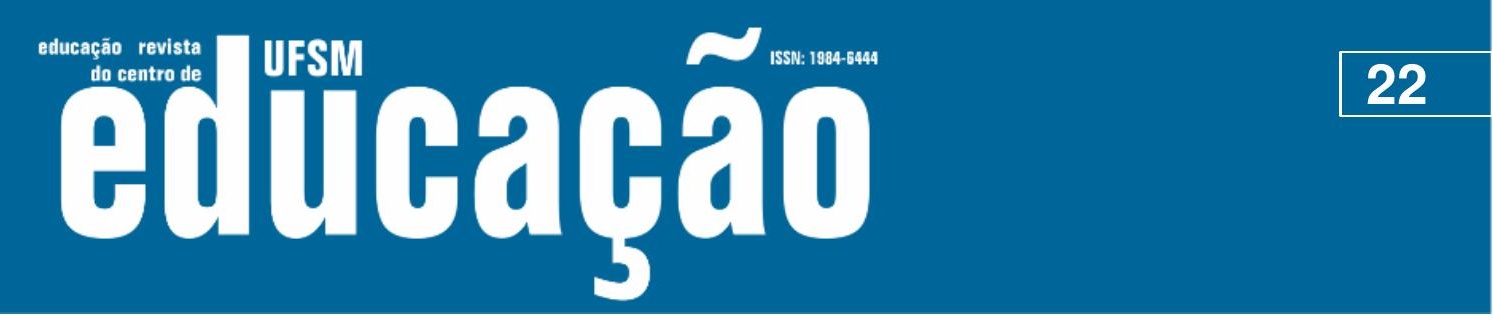

ISSN: 1984-6444 | http://dx.doi.org/10.5902/1984644448049

que não alterem a estrutura social, é sempre possível ir além e plantar nas pequenas brechas as sementes que podem florescer a autonomia do grupo.

\section{Referências}

BAUMAN, Zygmunt. Confiança e medo na cidade. In: BAUMAN, Zygmunt. Confiança e medo na cidade. Rio de Janeiro: Jorge Zahar, 2009, p. 13-51.

BEHRING, Elaine Rossetti; BOSCHETTI, Ivanete. Política social: fundamentos e história. 9. ed. São Paulo: Cortez, 2011

BEHRING, Elaine Rossetti. Trabalho e Seguridade Social: neoconservadorismo nas políticas sociais. In: BEHRING, Elaine Rosseti. ALMEIDA, Maria Helena Tenório de (orgs.). Trabalho e seguridade social: percursos e dilemas. 2. ed. Rio de Janeiro: Cortez, 2010, p. 152-174

BOSCHETTI, Ivanete. Capitalismo em crise: política social e direitos. São Paulo: Cortez, 2010.

BRANDÃO, Carlos Rodrigues. O que é educação? São Paulo: Brasiliense, 2007. Coleção Primeiros Passos, n. 20.

BRASIL, Política Nacional de Assistência Social - PNAS, aprovada pelo Conselho Nacional da Assistência Social por intermédio da Resolução no 145, de 15 de outubro de 2004 e publicada no DOU de 28 de outubro de 2004.

BRASIL. Ministério do Desenvolvimento Social e Combate à Fome. Orientações Técnicas sobre o PAIF. O Serviço de Proteção e Atendimento Integral à Família PAIF, segundo a tipificação nacional de serviços socioassistenciais. Vol. 1. Brasília: MDS, 2012.

BRASIL. Ministério do Desenvolvimento Social e Combate à Fome. Tipificação Nacional dos Serviços Socioassistenciais. Brasília: MDS, 2014.

CARLOTO, Cássia M. MARIANO, Silvana A. No meio do caminho entre o privado e o público: um debate sobre o papel das mulheres na política de assistência social. In: Rev. Estudos Femininos. Florianópolis, vol.18, n.2, p. 451-471, mai./ago., 2010. Disponível em: http://www.scielo.br/scielo.php?script=sci_abstract\&pid=S0104026X2010000200009\&lng=pt\&nrm=iso\&tlng=pt. Acesso em 01 dez. 2018.

CHARLOT, Bernard. A mistificação pedagógica: realidades sociais e processos ideológicos na teoria da educação. $2^{\mathrm{a}}$ ed. Rio de janeiro: Editora Guanabara, 1986. 


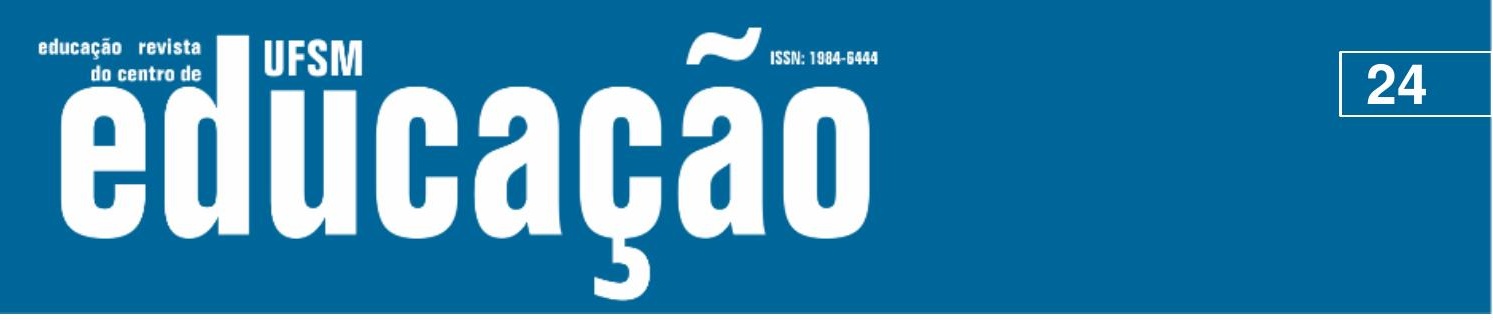

ISSN: 1984-6444 | http://dx.doi.org/10.5902/1984644448049

MARTINS, Marcos Francisco. Educação sócio-comunitária em construção. In: Revista HISTEDBR On-line, Campinas, n.28, p.106-130, dez. 2007. Disponível em: http://www.histedbr.fe.unicamp.br/revista/edicoes/28/art08_28.pdf. Acesso em 16 Nov. 2017.

MATOS, Olgária. Walter Benjamin: polis grega, metrópoles modernas. In: JOBIM e SOUZA, Solange; KRAMER, Sonia. Política, cidade, educação: itinerários de Walter Benjamin. Rio de Janeiro: Contraponto/PUC-Rio, p. 61-84, 2009.

PICHETH, Sara Fernandes; CHAGAS, Priscilla Borgonhoni. Interfaces entre territorialidade e identidade: analisando as vivências das mães do Grupo Maternati. Cad. EBAPE.BR, Rio de Janeiro, v. 16, n. 4, p. 788-801, dezembro de 2018. Disponível em http://www.scielo.br/scielo.php?script=sci_arttext\&pid=S1679$39512018000400788 \&$ Ing=en\&nrm=iso. acesso em 20 de maio de 2019.

SANTOS, Boaventura de Sousa. Para além do pensamento abissal: das linhas globais a uma ecologia de saberes. In: Novos estud. - CEBRAP, São Paulo, n. 79, Nov. 2007, p. 71-94. Disponível em: http://www.scielo.br/pdf/nec/n79/04.pdf. Acesso em: 07/09/2018.

SANTOS, Josiane Soares. Questão Social: particularidades no Brasil. São Paulo: Cortez, 2012.

SPIVAK, Gayatri Chakravorty. Pode o subalterno falar? 1. ed. Trad. Sandra Regina Goulart Almeida; Marcos Pereira Feitosa; André Pereira. Belo Horizonte: Editora da UFMG, 2010.

WALLERSTEIN, Immanuel Maurice. Capitalismo histórico e civilização capitalista. Rio de Janeiro: Contraponto, 2001.

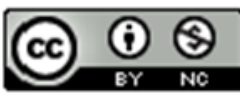

This work is licensed under a Creative Commons Attribution-NonCommercial 4.0 International (CC BY-NC 4.0)

\section{Notas}

\footnotetext{
1 Alusão à roda de conversa, sistema em que é realizado o grupo.

2 As abordagens e os instrumentos metodológicos utilizados obedeceram aos procedimentos éticos estabelecidos para a pesquisa científica em Ciências Humanas e o projeto investigativo foi aprovado pelo parecer no. 2.808.403.
} 